\title{
Application of Network Technology in Electrical Engineering and Its Automation
}

\author{
Ming $\mathrm{Hu}$ \\ NanChang Institute of Science \& Technology, Nanchang, 330108
}

\begin{abstract}
Keywords: Network technology; Artificial intelligence; Electrical engineering; Electrical automation
\end{abstract}
\begin{abstract}
In the current situation of rapid economic development, people's living standards have been improved, and much higher requirements on the quality of service has been put forward. The modern scientific and technological strength has also promoted the continuous improvement of industrial level in China. The competition in the market economy conditions prompt the means of competition and mechanisms continue to be improved, if the enterprises want to gain more benefits in the fierce market, they must constantly improve their own technical level, improve their hematopoietic capacity, fully realize business healthy and sustainable development, driven by science and technology, the industry and the Internet come to be combined, the applications of network technology promote the enterprise to reach a higher level of development, so that business scale and economic benefits are improved simultaneously, network technology has been widely promoted and applied in electrical engineering automation, which lead to the work efficiency has been improved fully, saving business costs and bringing good economic and social benefits for the development of enterprises.
\end{abstract}

\section{Introduction}

Electrical engineering and its automation technology is one of the most widely used technologies in the field of industrial production, including electrical and electronic technology and computer technology. As the included areas are relatively wide, so its core strength is also strong. So, for electrical engineering and its automation technology, the most important one of its technical characteristics is the automation model and philosophy. The concept and technology model of automation has become one of the major technologies in industry and manufacturing. However, with the growing demand for the market, for the traditional electrical engineering and automation technology, the current technology can not meet market demand, which requires further development of the original technology, artificial intelligence is development direction in the future, while in electrical engineering and automation technology, the application of network technology is also very necessary. Therefore, the appropriate development of network technology and its application in electrical engineering and automation technology is very essential.

\section{Artificial Intelligence Concept}

Artificial intelligence is a kind of modern intelligent technology, it is a method that mainly through the development and utilization of artificial limits, to reach the artificial imitation, extension and expansion and comprehensively increase human intelligence, to make the machine more intelligent and automatic, in line with the actual needs. The development of modern technology promote the development of artificial intelligence, it can be said that artificial intelligence is the application of human exploration of science. Mankind has been using tools from the beginning of the production, which is the fundamental difference between human and animals, people use a variety of production tools to transform nature, improve their living conditions, to create another way to achieve the natural reengineering.

Intelligent technology is the development of computer technology, based on the computer platform, develop completely new computer-based platform for intelligent technology. At present, the application of the intelligent technology in the field of intelligent robots is the most extensive, and the development of the effect is also very obvious, can achieve a certain degree of intelligent 
operation purposes. Intelligent technology can be divided into artificial intelligence and intelligent two aspects. Artificial intelligence is generally simulated human mind to judge and think, it mainly can achieve to independent operation and control, which to a certain extent, to achieve the effect of intelligent and purpose. At present, computer technology-based intelligent technology development has also encountered bottlenecks, but the current intelligent technology is still very intelligent, and they can solve many problems in production and manufacturing industry.

\section{Application of Electrical Automation Technology in Electrical Engineering}

Remote Monitoring Technology in Electrical Engineering Applications. Remote monitoring technology is using computers to take remote monitoring for equipment. It can timely find the work situation of the equipment, not only can reduce the cost of manual installation, material costs and other expenses, but also improve work efficiency. Besides, remote monitoring technology can be limited by time and place restrictions on the engineering technology to achieve remote monitoring and management, but also more conducive to the management of equipment to improve the timeliness and reliability of the management of. Remote monitoring technology in the electrical engineering application is more conducive to the present management

of electrical engineering.

Applications of Centralized Monitoring Technology in Electrical Engineering. The application of centralized monitoring technology in electrical engineering has changed the way of multiple processor monitoring. It can monitor the multiple systems with only one processor, which can reduce the maintenance cost and improve the work efficiency of the maintenance personnel, the requirement of the system for centralized monitoring system are not high, simple design, easy to operate and easy to carry out equipment maintain every day. And the centralized monitoring system in the electrical engineering application makes electrical equipment in the whole electrical engineering run effectively, thereby reducing the loss because of not work of the equipment.

Applications of Fieldbus Monitoring Technology in Electrical Engineering. The application of fieldbus monitoring technology in electrical engineering is the most important and it has many advantages. Fieldbus monitoring technology has good pertinence and it can reduce the demand for electric equipment, because fieldbus monitoring technology can effectively reduce the demand for equipment application. And all the equipment in the fieldbus monitoring system is connected by means of communication network, making the fieldbus monitoring technology has the flexibility and independence, if a device broken in the process of running will cause the entire power system paralysis, The corresponding loss can be reduced, improve the safety and reliability of the entire power system, but also to ensure the normal operation of the power system to ensure that users can use a safe, efficient and sustainable electricity to meet the user's production needs of life.

\section{Application of Network Intelligent Technology in Electrical Engineering and its Automation}

Substation Automation in Electrical Engineering. Electrical engineering automation level is the requirements of the times, but also the needs of life, it is already imminent in the development process, the substation is the most important part in electrical engineering, is the main core. It plays the central role in the use of electronic engineering and promotion, through the use of intelligent technology to replace the traditional manual operation, it can improve the actual operation of the substation capacity, so that the monitoring and inspection are more accurate, to achieve computer networking information and automation, computer cable applications, to further improve the power signal strength, and achieve the data transmission efficiency and accuracy.

Electrical Engineering Control System Automation. The more developed of the economy, the more environmental requirements have been improved, in the rapid economic development of the case, China's continuously pursuit of environmental protection, so that industrial production tend to a more healthy direction, building a conservation economy has become a common pursuit of contemporary enterprises. Only by continuously promoting the electrical engineering to optimize the direction of the development of resources in order to ensure the safety and reliability of 
electrical engineering, electrical engineering in the use of intelligent devices can achieve a rapid response to the work efficiency, in the system control, it can effectively achieve more rapid and efficient for intelligent data processing, data analysis are more quickly and effectively, intelligent technology applications and control, from the nature of the conservation of human labor, greatly reduced labor costs and the cost of labor and time, so that enterprises achieve a conservation-oriented economic development model, forming a high-quality economies of scale and efficiency.

Accurate Diagnosis and Find Fault. In the process of electrical engineering operations, it will find the situation of mechanical equipment problems. This is the case where any industry can not avoid. It is necessary to carry out timely inspection and maintenance of related equipment, while manual inspection is generally by virtue of their own experience. But sometimes, the experience will be a mistake, which will lead to mechanical failure and can not be got timely maintenance, resulting in a certain loss. Therefore, when the automation of intelligent technology appears, so that it is used in electrical engineering equipment in the diagnosis and fault to find work, can accurately determine the problems, as well as the specific reasons of the emergence, which can be targeted to solve the problem in the equipment, to avoid a large area of equipment damage.

\section{Conclusion}

Through the analysis on intelligent technology, we understand that intelligent technology is still built on the computer platform, or based on a derivative of computer technology. Intelligent technology is the most potential development of artificial intelligence technology. At present, the development of electrical engineering and its automation technology has encountered bottlenecks, and it is necessary to combine the application of intelligent technology to solve the existing problems effectively, so as to realize the further efficient application of electrical engineering and automation technology. In short, electrical engineering technology is inseparable from the electronic power technology and computer technology, and intelligent technology is also inseparable from the computer technology. Therefore, the two sides have a certain degree of inevitable link, which is the premise for combination of application development. In a word, the intelligent technology make electrical engineering more intelligent and efficient, and electrical engineering and related fields get a qualitative leap.

\section{Acknowledgement}

Project Funding: Jiangxi Province Features Major（No. : NGTSZY201001）

\section{References}

[1] Kikuchi J. Challenging Questions for Power Electronics Engineers/Researchers in Vehicle Electrification[C]// IEEE Apec. IEEE, 2015.

[2] Criqui L. The electrification of irregular settlements in Lima: Catching up on steep slopes[J]. Flux, 2015, 99(1):5-18.

[3] Bucci V, Marino A, Bosich D, et al. Inland waterway gas-fueled vessels: CASM-based electrification of a pushboat for the European network[J]. IEEE Transactions on Transportation Electrification, 2016, PP(99):1-1.

[4] Hamaguchi T. Feature quantities for analysis of digital spike maps[J]. Chinese J Comput, 2016, 8(12):2291-2299.

[5] Ahmed M R, Hazra S R, Rahman M M, et al. Solar-Biomass Hybrid System; Proposal for Rural Electrification in Bangladesh[J]. 2015, 4:1-11.

[6] Krastev I, Tricoli P, Hillmansen S, et al. Future of Electric Railways: Advanced Electrification Systems with Static Converters for ac Railways[J]. IEEE Electrification Magazine, 2016, 4(3):6-14.

[7] Cao H, Sun Y, Yuan Q, et al. Time domain characteristics of isolated conductor surface 
electrification by electronic irradiation inside spacecraft[J]. Gaodianya Jishu/high Voltage Engineering, 2015, 41(3):991-997.

[8] Kikuchi J. Challenging Questions for Power Electronics Engineers/Researchers in Vehicle Electrification[C]// IEEE Apec. IEEE, 2015.

[9] Raheem A. Economic Feasibility of Stand-Alone Wind Energy Hybrid with Bioenergy from Anaerobic Digestion for Electrification of Remote Area of Pakistan[J]. International Journal of Integrated Engineering, 2015, 06(3):1-7.

[10] Movahed Nejad M. Frontiers in operations research for overcoming barriers to vehicle electrification[J]. Dissertations \& Theses - Gradworks, 2015.

[11] Rasmussen T B, Wu Q, Huang S. Real time emulation of dynamic tariff for congestion management in distribution networks[C]// Energy, Power and Transportation Electrification. IEEE, 2017.

[12]Zhang S, Malik S. Feasibility Study of Solar Energy Steam Generator for Rural Electrification[J]. Energy \& Power Engineering, 2015, 7(1):1-11. 